\title{
Left Atrial Thrombus After Placement of Watchman Device
}

\author{
Emmanuel Isang ${ }^{1}$, Shawna Stephens ${ }^{1}$, Tyler Coombes ${ }^{1}$, Lon Abney ${ }^{1}$, and Gayathri \\ Baljepally $^{2}$ \\ ${ }^{1}$ The University of Tennessee Graduate School of Medicine \\ ${ }^{2}$ The University of Tennessee Medical Center
}

February 22, 2022

\begin{abstract}
Atrial fibrillation is an irregular heart rhythm with increased risk of morbidity and mortality. Commonly due to thromboembolism at the left atrial appendage. Guideline therapy for atrial fibrillation is anticoagulation. Alternative treatment includes closure with the Watchman device. We present a case of Watchman device-related thrombus seven months after placement.
\end{abstract}

Author : Emmanuel Isang, $\mathrm{MD}^{1}$

Co Authors : Shawna Stephens, $\mathrm{DO}^{1}$; Tyler Coombes, $\mathrm{MD}^{1}$; Lon Abney, $\mathrm{MD}^{1}$; Gayathri Baljepally, $\mathrm{MD}^{2}$ Affiliations:

Graduate School of Medicine, University of Tennessee ${ }^{1}$, Knoxville, TN

University of Tennessee Medical Center ${ }^{2}$, Knoxville, TN

Case

74-year-old male with history of chronic atrial fibrillation presents with 5 days of abdominal pain and dyspnea. 7 months prior, he underwent placement of a Watchman device due to nonadherence with apixaban 5mg twice daily. Transesophageal echocardiogram (TEE) revealed a large thrombus, measuring $2.9 \times 1.9 \mathrm{~cm}$, seated on top of the Watchman device (Figure 1). At the time of presentation, he was taking aspirin $325 \mathrm{mg}$ daily. He inadvertently stopped taking aspirin and clopidogrel 2 months earlier than recommended and had a 10-day interruption of aspirin for screening colonoscopy. He was discharged on apixaban $5 \mathrm{mg}$ twice daily and aspirin $325 \mathrm{mg}$ daily. Follow up TEE 4 months later revealed reduced size of thrombus, measuring 0.70 x $0.86 \mathrm{~cm}$ (Figure 2).

Atrial fibrillation is the most common cardiac arrhythmia that we face, affecting millions of people worldwide. It carries the risk of stroke, especially in those with elevated CHA2DS2-VASc score, necessitating use of anticoagulation. In those who risk of bleeding outweighs the benefit, left atrial appendage closure device, such as the Watchman, is a great alternative and has been shown to be noninferior in the PROTECT AF study.2 It, however, does carry its own risk such as device-related thrombus.1

\section{Acknowledgement}

I would like to thank Drs. Stephens, Coombes, and Abney for all their effort in assisting in writing this paper. I wish to acknowledge the help provided by Dr. Baljepally, who helped us finalized this project.

\section{Hosted file}

Watchman TEE.docx available at https://authorea.com/users/461884/articles/557461-left-atrialthrombus-after-placement-of-watchman-device 


\section{Hosted file}

Watchman TEE 2.docx available at https://authorea.com/users/461884/articles/557461-leftatrial-thrombus-after-placement-of-watchman-device

\section{Hosted file}

Acknowledgement.docx available at https://authorea.com/users/461884/articles/557461-leftatrial-thrombus-after-placement-of-watchman-device 